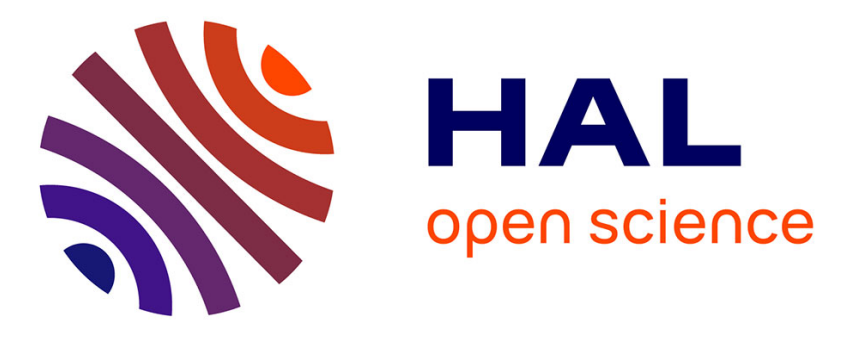

\title{
Experimental and theoretical charge-density analysis of 1,4-bis(5-hexyl-2-thienyl)butane-1,4-dione: applications of a virtual-atom model
}

Maqsood Ahmed, Ayoub Nassour, Sajida Noureen, Claude Lecomte, Christian Jelsch

\section{To cite this version:}

Maqsood Ahmed, Ayoub Nassour, Sajida Noureen, Claude Lecomte, Christian Jelsch. Experimental and theoretical charge-density analysis of 1,4-bis(5-hexyl-2-thienyl)butane-1,4-dione: applications of a virtual-atom model. Acta Crystallographica Section B : Structural Science, Crystal Engineering and Materials [2014-..], 2016, 72 (1), pp.75-86. 10.1107/S2052520615019083 . hal-02364996

\section{HAL Id: hal-02364996 https://hal.science/hal-02364996}

Submitted on 15 Nov 2019

HAL is a multi-disciplinary open access archive for the deposit and dissemination of scientific research documents, whether they are published or not. The documents may come from teaching and research institutions in France or abroad, or from public or private research centers.
L'archive ouverte pluridisciplinaire HAL, est destinée au dépôt et à la diffusion de documents scientifiques de niveau recherche, publiés ou non, émanant des établissements d'enseignement et de recherche français ou étrangers, des laboratoires publics ou privés. 
ISSN: 2052-5206

journals.iucr.org/b

\section{Experimental and theoretical charge-density analysis of 1,4-bis(5-hexyl-2-thienyl)butane-1,4-dione: applications of a virtual-atom model}

\section{Maqsood Ahmed, Ayoub Nassour, Sajida Noureen, Claude Lecomte and Christian Jelsch}

Acta Cryst. (2016). B72, 75-86

\section{:}

\section{IUCr Journals}

\section{CRYSTALLOGRAPHY JOURNALS ONLINE}

Copyright (C) International Union of Crystallography

Author(s) of this paper may load this reprint on their own web site or institutional repository provided that this cover page is retained. Republication of this article or its storage in electronic databases other than as specified above is not permitted without prior permission in writing from the IUCr.

For further information see http://journals.iucr.org/services/authorrights.html 
STRUCTURAL SCIENCE CRYSTAL ENGINEERING MATERIALS

ISSN 2052-5206

Received 26 June 2015

Accepted 9 October 2015

Edited by T. N. Guru Row, Indian Institute of Science, India

Keywords: multipolar modeling; electron density; spherical scatterers.

CCDC reference: 1430523

Supporting information: this article has supporting information at journals.iucr.org/b

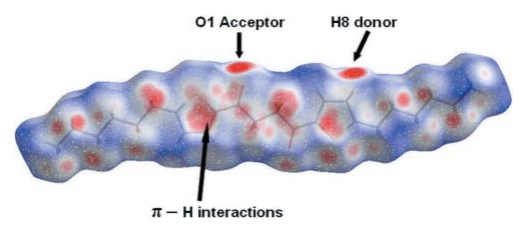

(C) 2016 International Union of Crystallography

\section{Experimental and theoretical charge-density analysis of 1,4-bis(5-hexyl-2-thienyl)butane-1,4- dione: applications of a virtual-atom model}

\author{
Maqsood Ahmed, ${ }^{\text {a,b }}$ Ayoub Nassour, ${ }^{b}$ Sajida Noureen, ${ }^{a}$ Claude Lecomte ${ }^{b}$ and \\ Christian Jelsch ${ }^{\mathbf{b}}$.
}

\begin{abstract}
${ }^{\mathbf{a}}$ Department of Chemistry, The Islamia University of Bahawalpur, 63100, Pakistan, and ${ }^{\mathbf{b}}$ Laboratoire de Cristallographie, Résonance Magnétique et Modélisations, CNRS UMR 7036 CRM2, Université de Lorraine, BP 70239, 54506, France. ${ }^{*}$ Correspondence e-mail: christian.jelsch@univ-lorraine.fr
\end{abstract}

The experimental and theoretical charge densities of 1,4-bis(5-hexyl-2thienyl)butane-1,4-dione, a precursor in the synthesis of thiophene-based semiconductors and organic solar cells, are presented. A dummy bond charges spherical atom model is applied besides the multipolar atom model. The results show that the dummy bond charges model is accurate enough to calculate electrostatic-derived properties which are comparable with those obtained by the multipolar atom model. The refinement statistics and the residual electron density values are found to be intermediate between the independent atom and the multipolar formalisms.

\section{Introduction}

Oligothiophenes are a promising class of organic semiconductor materials, which are finding a variety of applications, e.g. in the production of cheap solution processed organic field-effect transistors with a large implementation as electronic devices (Ponomarenko \& Kirchmeyer, 2003; Barbarella et al., 2005). Many chemical modifications, such as ring fusion (Zhang et al., 2005), chain-length elongation (Izumi et al., 2003; Ie et al., 2009) (i.e. up to the 96-mer), replacement of sulfur by other heteroatoms (Yamamoto \& Takimiya, 2007; Izawa et al., 2009), substitution of the $\alpha$-terminal and $\beta$-inner positions with alkyl and electroactive groups (Ellinger et al., 2007; González et al., 2008), combination with acenes (Nicolas et al., 2005; Fritz et al., 2007), selective sulfur oxidation (Barbarella et al., 2005) and so on have been reported

Therefore, the investigation of well defined oligomers has become attractive for gaining insight into the structural and electronic properties of these materials. A profound knowledge of the electronic environment of a molecule is important for understanding its chemical reactions.

The title compound (I) is a precursor for the synthesis of a variety of organic semiconductor devices (Perepichka \& Perepichka, 2009). Its charge density has been determined both experimentally and theoretically. A model based on dummy bond charge (virtual atoms modelling) was refined against both the experimental and the theoretical structure factors for the target molecule (I).

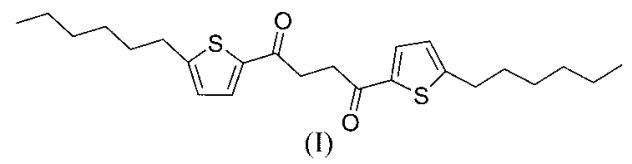


This approach allows the modelling of electron density as an alternative to the classical Hansen-Coppens (Hansen \& Coppens, 1978) multipolar atom model. Such spherical charges modelling has already been applied in a few cases, for example, in the work by Mullen \& Hellner (Scheringer et al., 1978) on thiourea and by Scheringer (1980) on silicon. More recently, the modelling of bond scatterers was applied by Afonine et al. $(2004,2007)$ in the refinement of proteins at ultra-high resolution. The dummy bond charge model used in this study was previously described by Dadda et al. (2012) and Nassour et al. (2014).

Improvements in the residual electron density and crystal$\operatorname{lographic} R$ factors upon electron density transfer are thoroughly discussed for the different models. The charge-density features and the derived molecular electrostatic potential are analysed.

\section{Materials and methods}

\subsection{Synthesis and crystallization}

The molecule was synthesized according to the method reported by Oliva et al. (2010). The yellowish crystals were obtained by the slow evaporation of a chloroform solution at room temperature. A highly diffracting single crystal with dimensions $0.43 \mathrm{~mm} \times 0.14 \mathrm{~mm} \times 0.084 \mathrm{~mm}$ was chosen for experiment.

${ }^{1} \mathrm{H}$ NMR $\left(250 \mathrm{MHz}, \mathrm{CDCl}_{3}\right): \delta$ (p.p.m.) $=7.64(d, 2 \mathrm{H}$ thiophene, $J=3.75 \mathrm{~Hz}), 6.82(d, 2 \mathrm{H}$ thiophene, $J=3.73 \mathrm{~Hz}), 3.43$ $(s, 4 \mathrm{H}), 2.94(t, 4 \mathrm{H}$ hexyl), $1.80(m, 4 \mathrm{H}$ hexyl), $1.44(m, 12 \mathrm{H}$ hexyl), 1.00 ( $m, 6 \mathrm{H}$ hexyl).

${ }^{13} \mathrm{C}$ NMR $\left(250 \mathrm{MHz}, \mathrm{CDCl}_{3}\right): \delta$ (p.p.m.) $=195.89,156.26$, 141.62, 132.68, 125.76, 33.24, 31.84, 31.70, 31.03, 29.07, 22.89, 14.43 .

\subsection{Data collection}

The data were collected on an Oxford Diffraction Supernova Dual Wavelength Microfocus diffractometer equipped with an ATLAS CCD detector using Mo $K \alpha$ radiation $(\lambda=$ $0.71073 \AA$ ) (Gál et al., 2011). The crystal was mounted on a glass needle using silicone grease. The crystal was cooled from room temperature to $100 \mathrm{~K}$ over a period of almost $30 \mathrm{~min}$ under a stream of nitrogen gas using the Oxford Cryosystems gas flow apparatus. The temperature was stable up to $\pm 1 \mathrm{~K}$. Details of data collection and refinement are given in Table 1. The SuperNova diffractometer works under the software CrysAlisPro (Agilent, 2010) which calculates the strategy to optimize the angular positions of the detector and the goniometer head during the data collection. Bragg intensities were collected using $1.0^{\circ}$ width $\omega$ scans and 75 s per frame exposure time resulting in a total of 70042 reflections and up to a $\sin \theta / \lambda$ $=1.026 \AA^{-1}$. Indexing, integration and scaling were performed with CrysAlisPro, Version 1.171.35.15 (Agilent, 2010). An analytical absorption correction (Clark \& Reid, 1995) was carried out by using the real face indexes of the crystal. The data sets were merged using SORTAV (Blessing, 1997) giving
Table 1

Crystal and data collection statistics.

\begin{tabular}{|c|c|}
\hline \multicolumn{2}{|l|}{ Crystal data } \\
\hline Chemical formula & $\mathrm{C}_{24} \mathrm{H}_{34} \mathrm{O}_{2} \mathrm{~S}_{2}$ \\
\hline$M_{\mathrm{r}}$ & 418.63 \\
\hline Crystal system, space group & Triclinic, $P \overline{1}$ \\
\hline Temperature (K) & $100(1)$ \\
\hline$a, b, c(\AA)$ & $5.047(5), 6.979(6), 16.333(9)$ \\
\hline$\alpha, \beta, \gamma\left({ }^{\circ}\right)$ & $98.79(16), 93.52(15), 95.39(15)$ \\
\hline$V\left(\AA^{3}\right)$ & $564.4(9)$ \\
\hline$Z$ & 1 \\
\hline Radiation type & Мо $K \alpha$ \\
\hline$\lambda(\AA)$ & 0.71073 \\
\hline$F(000)$ & 226 \\
\hline Crystal shape & Rectangular block \\
\hline Colour & Yellowish \\
\hline Crystal dimensions (mm) & $0.43 \times 0.14 \times 0.08$ \\
\hline \multicolumn{2}{|l|}{ Data collection } \\
\hline Diffractometer & Oxford SuperNova four-circle \\
\hline Absorption correction & Analytical (Clark \& Reid, 1995) \\
\hline Absorption coefficient $\mu\left(\mathrm{mm}^{-1}\right)$ & 0.252 \\
\hline$T_{\min }, T_{\max }$ & $0.932,0.980$ \\
\hline $\sin \theta_{\max } / \lambda\left(\AA^{-1}\right)$ & 1.026 \\
\hline $\begin{array}{l}\text { No. of measured, unique, used reflec- } \\
\text { tions }\end{array}$ & 70 042, 10 227, 9169 \\
\hline No. of reflections $(I>2 \sigma)$ & 9170 \\
\hline Completeness (\%) at $\sin \theta_{\max } / \lambda$ & 99.94 \\
\hline Completeness at $\theta_{\max }(\%)$ & 94.8 \\
\hline$R_{\text {int }}$ & 0.053 \\
\hline
\end{tabular}

10227 unique reflections. The average redundancy of the data was 6.8 .

\section{Crystallographic refinements}

\subsection{Experimental data}

3.1.1. IAM refinement. The structure was initially solved in space group P1 using SIR92 software (Altomare et al., 1993) and then refined in space group $P \overline{1}$. Independent-atom model (IAM) refinement was undertaken using the SHELXL97 program (Sheldrick, 2008). All H atoms were easily located during the structure solution (see Fig. 1).

The deformation electron density map calculated after IAM refinement is shown in Fig. S1 (supporting information). From this Fourier map, the accuracy of the diffraction data can be easily judged. The peaks of residual electron density are very

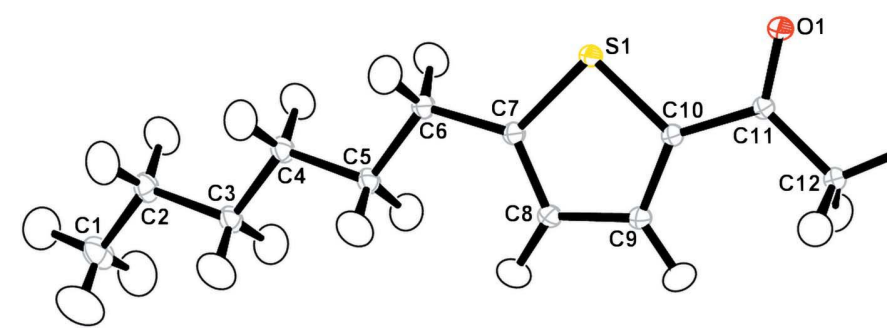

Figure 1

An ORTEP (Johnson \& Burnett, 1996; Farrugia, 1997) diagram of the asymmetric unit. The displacement ellipsoids are drawn at $50 \%$ probability. The $\mathrm{H}$-atom labels (not shown) correspond to their $\mathrm{C}$ atoms. 
well placed on the covalent bonds. The $\mathrm{H}$ atoms are clearly located and the lone pairs on the $\mathrm{O}$ and the $\mathrm{S}$ atoms are distinctly visible.

3.1.2. Experimental multipolar refinement strategy. The multipolar refinement of (I) was carried out with MoPro (Jelsch et al., 2005) using the Hansen-Coppens (Hansen \& Coppens, 1978) multipolar atom model using an $I / \sigma>2$ cutoff on reflections during all of the steps. During the multipolar refinement, $\mathrm{H}$-atom positions were constrained to the standard neutron $\mathrm{C}-\mathrm{H}$ distances as available in International Tables of Crystallography (Allen, 1986) and their anisotropic displacement parameters (ADPs) constrained to the values obtained from the SHADE server (Madsen et al., 2004). C and $\mathrm{O}$ atoms were modelled to octapolar level, the $\mathrm{S}$ atom to hexadecapolar level and the $\mathrm{H}$ atoms to dipolar level. The core and valence scattering factors were calculated from the Clementi \& Roetti (1974) wavefunctions.

The $\kappa$ parameters for similar $\mathrm{H}$ atoms were restrained to a value of 1.16 (Stewart, 1976) with an allowed uncertainty of 0.01 . Local symmetry and chemical equivalence restraints were generated automatically by the program MoPro. The weighting scheme was adjusted $w=1 /\left[\sigma^{2}\left(F_{\mathrm{o}}^{2}\right)+(0.007 P)^{2}+\right.$
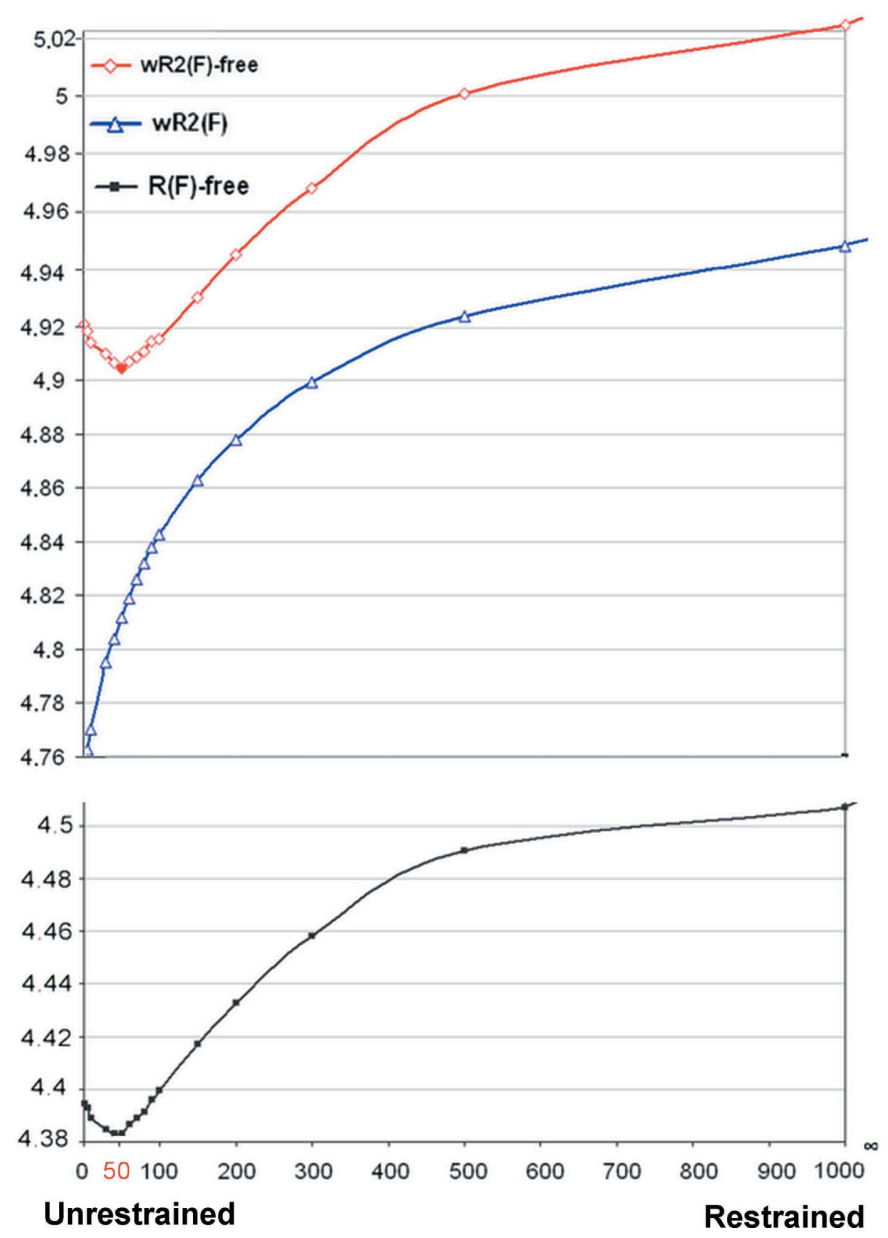

Figure 2

Free $w R_{2}(F), w R_{2}(F)$ and $R_{\text {free }}(F)$ factors as a function of weight applied on charge-density restraints $\left(\kappa, P_{\mathrm{val}}\right.$ and $P_{\mathrm{lm}}$ similarity and multipoles local symmetry.
$0.4 P$ ], where $P=\left(F_{\mathrm{o}}^{2}+2 F_{\mathrm{c}}^{2}\right) / 3$ in order to have a goodness-offit close to unity. The plots of the $X D R K$ program (Zhurov et $a l ., 2008)$ are shown in the supporting information. The $U^{i j}$ and $x y z$ parameters of all the non- $\mathrm{H}$ atoms were refined using the high-order reflections, $s>0.7 \AA^{-1}(s=\sin \theta / \lambda)$, to ensure the deconvolution of the thermal motion from the deformation electron density (Hirshfeld, 1976). Later, these parameters were refined using all reflections. Then the charge-density parameters $k, k^{\prime}, P_{\text {val }}$ and $P_{\mathrm{lm}}$ were refined successively. In the last cycles of the refinement all parameters were refined together until convergence.

3.1.3. $\boldsymbol{R}_{\text {free }}$ factor. The constrained multipolar refinement does not show the effects of the molecular interactions on the electron density. Therefore, to avoid possible over-fitting of the data in the refinement procedure and to find out the best restraints model, $R_{\text {free }}$ calculations were performed. The conventional $R$ factor is not an objective indicator of the quality of the model. Brünger $(1992,1997)$ proposed another more reliable criterion called the $R_{\text {free }}$ factor to judge the quality of the crystallographic model. The $R_{\text {free }}$ analysis is considered a better tool for validation of the refined model as its value increases if the experimental data are over-fitted. An $R_{\text {free }}$ test has been recently applied to charge-density analyses (Domagała \& Jelsch, 2008; Zarychta et al., 2011; Paul et al., 2011; Ahmed, Yar et al., 2013). $R_{\text {free }}$ factor analyses can determine to what extent chemical equivalence and local symmetry constraints/restraints can be released.

In the $R_{\text {free }}$ refinements, $5 \%$ of the reflections were omitted as a test subset and the remaining $95 \%$ were used in the leastsquares refinement. Twenty refinements with complementary

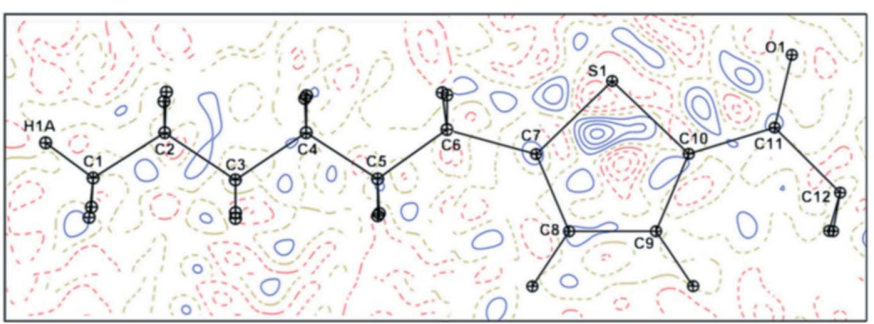

(a)

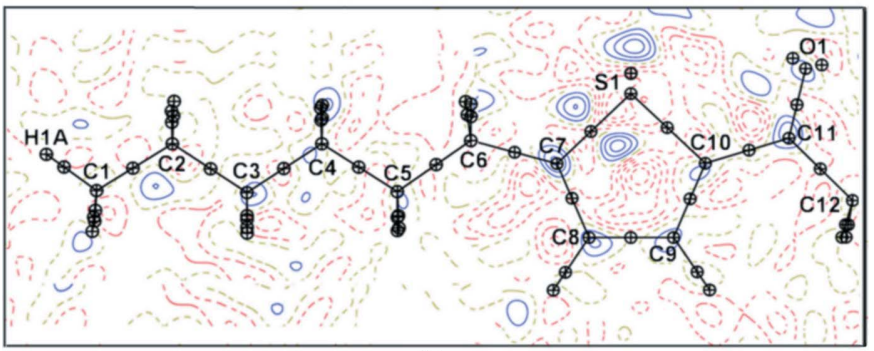

(b)

Figure 3

Fourier residual electron density after (a) EXP_MUL and (b) EXP_VIR refinements. The Fourier synthesis is truncated at $s<0.7 \AA^{-1}$. Solid blue lines represent the positive electron density and dashed red lines the negative electron density (contour levels $\pm 0.05 \mathrm{e}^{-3}$ ). The dashed yellow-green lines show the region where the electron density is zero. The figure consists of two left/right images merged near C6, in the planes of atoms $\mathrm{C} 9-\mathrm{C} 8-\mathrm{C} 7$ and $\mathrm{C} 2-\mathrm{C} 3-\mathrm{C} 4$. 
free reflection subsets were performed to obtain a global $R_{\text {free }}$ value. It was found that the sigma value $\sigma_{\mathrm{r}}=0.02$ on the charge-density restraints (chemical equivalence and local symmetry) gives the best $R_{\text {free }}$ factor statistics (Fig. 2).

This best restraints model obtained from the $R_{\text {free }}$ calculations was used for the final refinement. From the residual electron density plots obtained after multipolar refinement, it is clear that there is essentially no important non-modelled electron density left (Fig. 3a). However, despite the hexadecapolar modelling of the $\mathrm{S} 1$ atom a small residual peak is observed inside the thiophene ring, which may be related to the elongated $\mathrm{C} 7-\mathrm{S} 1$ bonding electron density found in the IAM residual map.

\subsection{Theoretical structure factors calculation}

Periodic quantum mechanical calculations using CRYSTAL06 (Dovesi et al., 2008) were performed at the crystal geometry observed experimentally and, using these data as a starting geometry, optimization was performed with the density functional theory (DFT) method (Hohenberg \& Kohn, 1964) and with the B3LYP hybrid functional (Lee et al., 1988; Becke, 1993) using the 6-31G (d,p) basis set (Hariharan \& Pople, 1973). The level of accuracy in evaluating the Coulomb and exchange series is controlled by five parameters for which the values of $10^{-6}, 10^{-6}, 10^{-6}, 10^{-6}$ and $10^{-17}$ were used for the Coulomb and exchange series. The shrinking factor of the reciprocal space was set to four, corresponding to $30 k$ points in the irreducible Brillouin zone at which the Hamiltonian matrix was diagonalized. Upon convergence on energy $\left(\Delta E \sim 10^{-8}\right)$, the periodic wavefunction based on the optimized geometry was obtained. The coordinates of $\mathrm{H}$ atoms were relaxed, but the unit cell was kept fixed. The index generation scheme proposed by Le Page \& Gabe (1979) was applied to generate 18616 unique Miller indices up to $s=$ $1.25 \AA^{-1}$ reciprocal resolutions. The option $X F A C$ of the CRYSTAL06 program was then used to generate a set of theoretical structure factors from the computed electron density and using a set of prepared indices. The theoretical charge density was refined versus all the generated structure factor amplitudes.

3.2.1. Multipolar refinement against theoretical structure factors. The multipole refinement based on the theoretical structure factors $F(h k l)$ was performed using 18616 unique Miller indices up to $s=1.25 \AA^{-1}$. The atomic positions were fixed to the values obtained from the geometry relaxation, the scale factor was fixed to unity and atomic thermal motion parameters were set to zero. The valence and multipole populations, and the $\kappa$ and $\kappa^{\prime}$ coefficients were refined sequentially in several cycles until convergence. Neither restraints nor constraints were imposed to the electron density distribution of the atoms, except for the $\mathrm{H}$ atoms, for which the $\kappa$ parameters were restrained to a value of $1.16(1)$. The residual electron density map is shown in Fig. 4(b).

It can be observed that generally the map is very clean. However, if compared with its experimental counterpart, some small positive density is left on the covalent bonds.
Similarly, negative electron density peaks are observed around the nuclei. The latter problem highlights the need for the correction of kappa of core electrons which will be discussed in the following section.

3.2.2. Kappa core correction. It was initially pointed out by Bentley \& Stewart (1974) that the core shell electrons might be polarized in the bonding process. Subsequent studies have revealed some commonly observed residual densities in experimental charge-density studies in the region of the core electrons, especially for heavy elements. This deficiency arises from an incomplete multipolar atom expansion neglecting the polarization of the core shell electrons (Pillet et al., 2001; Fischer et al., 2011; Overgaard et al., 2011; Farrugia \& Senn, 2012; Batke \& Eickerling, 2013; Bindzus et al., 2014). Therefore, the contribution of the core shell electrons may be corrected, using an additional expansion/contraction coefficient $\kappa_{\text {cor }}$.

The structure factors obtained from theoretical data in CRYSTAL06 software are derived from calculations using Gaussian functions. On the other hand, the electron density is modelled using Slater functions in the MoPro software. These different functions used result in slightly different modelling of the core shell electrons, which may be corrected using an additional expansion/contraction coefficient $\kappa_{\text {cor }}$. Fourier electron density maps actually yield strong residual peaks around the nuclei, which disappear upon refinement of this additional parameter. The $\kappa_{\text {cor }}$ parameter is refined in practice in MoPro by duplicating the non-H atoms at the same position, with the core electrons moved to the valence shell of the second copy of the atom. The kappa core refinement is applied here on relatively light elements $(\mathrm{C}, \mathrm{O}, \mathrm{S})$ to correct for the discrepancy between the mathematical modelling of the core electron density. The large improvement effect of the kappa core correction is shown in Figs. 4 and 5.

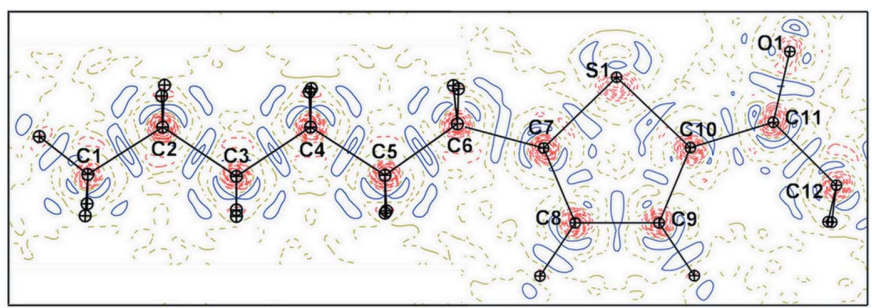

(a)

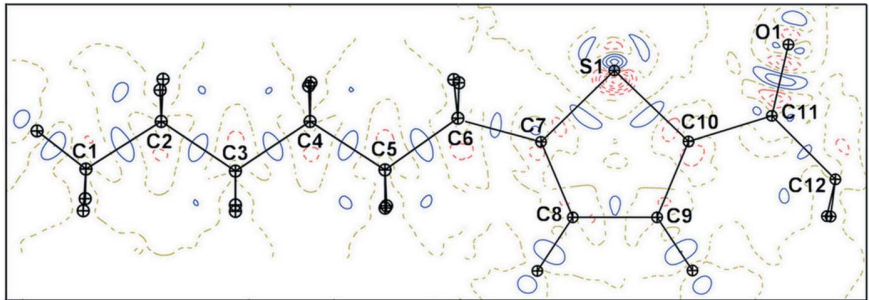

(b)

Figure 4

Fourier residual electron density maps for the THEO_MUL refinements: (a) without and (b) with kappa core correction. Resolution used: $s$ $<1.2 \AA^{-1}$. Contours as in Fig. 3 . 


\subsection{Virtual charge model applied to theoretical and experimental data}

The deformation electron density consists mostly of the accumulation of electrons on the covalent bonds and in the regions of the lone pairs. Based on these considerations, an empirical model that reproduces results of quality nearly comparable with the multipolar atom model was developed. In this model, the electron density is considered as a superposition of spherical and virtual atoms

$$
\rho(\mathbf{r})=\sum_{\text {atoms }}\left[\rho_{\text {core }}(\mathbf{r})+P_{\text {val }} \kappa^{3} \rho_{\text {val }}(\kappa r)\right]+\sum_{\text {vir }} P_{\text {val }}^{\mathrm{vir}} \kappa^{\mathrm{vir}} \rho_{\text {val }}^{\mathrm{vir}}(\kappa r),
$$

where $\rho_{\text {core }}$ and $\rho_{\text {val }}$, which are the core and spherical valence electron densities of the real atoms, can be calculated from Hartree-Fock (HF) or density functional theory (DFT). The real atoms $(\mathrm{C}, \mathrm{O}, \mathrm{S}$ and $\mathrm{H})$ are treated spherically and are described by the first and the second term of the equation. The third term indicates virtual density that is similar to the second term of the Hansen-Coppens equation with a spherical valence population and $\kappa^{\text {vir }}$ an expansion/contraction coefficient. The atomic wavefunctions by Clementi \& Roetti (1974) were used to model the real atoms.

A unique Slater-type wavefunction was adopted for all the dummy bond charges (DBC) as has already been described by Dadda et al. (2012) and by Nassour et al. (2014).

The $Q_{A B}$ and $Q_{\mathrm{Lp}}$ virtual atoms refer, in this article, to the bonding density between atoms $A$ and $B$ and to the charge located on the expected oxygen electron lone pair (Lp) sites, respectively. The $Q_{\mathrm{Lp}}$ atoms were assigned the same wavefunction description as the $Q_{A B}$ atoms but, as they are more contracted in space, refined to larger $\kappa$ values.

3.3.1. Restraints and constraints on virtual atoms. The position of the virtual spherical charge was stabilized by restrictions of stereochemistry (distances, angles, linearity and planarity...). The virtual atoms $Q_{A B}$ were allowed to move freely along the bond by using a geometrical linearity restraint on the $A-Q_{A B}-B$ triplets. The oxygen/sulfur electron lone pairs were stabilized by application of distance restraints $(X-$ $\mathrm{Lp}, X$ being $\mathrm{O}$ or $\mathrm{S})$, of distance similarity restraints $(X-\mathrm{Lp}=$ $\left.X-\mathrm{Lp}^{\prime}\right)$ and of angle similarity restraints $(A-X-\mathrm{Lp}=A-$ $\left.X-\mathrm{Lp}^{\prime}\right)$. The similarity restraints avoid using extra information besides the diffraction data. Planarity restraints were applied to the lone pairs belonging to the carbonyl $\mathrm{O}$ atom. Weights for geometry restraints on virtual atoms were $\sigma_{\mathrm{d}}=$ $0.01 \AA$ for distance, $\sigma_{\mathrm{sd}}=0.005 \AA$ for similarity of distance, $\sigma_{\mathrm{a}}$ $=0.1^{\circ}$ for similarity of angles and $\sigma_{\mathrm{p}}=0.001$ for planarity restraints, for both experimental and theoretical data refinements.

To reduce the number of the least-squares variables and to improve the convergence of the refinement, chemical equivalence constraints were imposed initially in the experimental refinement. In the final stages of refinement, the constraints were replaced by restraints, which rather increases the number of observations. In the case of the spherical atoms and virtual charges model, the chemical equivalence constraints apply to two parameters only: the $P_{\text {val }}$ and $P_{\text {vir }}$ valence populations and the expansion/contraction coefficient $\kappa$.

3.3.2. Virtual atoms: theoretical refinement. All atoms were modelled at the monopole level. The temperature factors and atomic positions were kept fixed to zero and the scale factor set to unity. The real atoms were kept fixed at the positions of the quantum calculation. The charge-density parameters of the initial theoretical model were set to the IAM model $\left(P_{\text {val }}=N_{\text {val }}, \kappa=1\right)$.

The only restraints applied were on the kappa coefficients of $\mathrm{H}$ atoms: $\kappa \simeq 1.16$ (1) (Stewart, 1976). Positional linearity constraints were applied to the bond charges.

The starting positions for all the additional charges were generated with the MoPro program. The bond virtual atoms were initially placed on the middle of the covalent bonds; the electron lone pairs were placed at their ideal positions (according to the restraints).

The refinement strategy was as follows:

(a) The starting valence population $P_{\text {val }}$ of all virtual charges was equal to zero. Therefore, the first parameters to be refined were the $P_{\text {val }}$ and $P_{\text {vir }}$ charges.

(b) Each type of parameter was refined successively: all valence populations, kappa parameters and the positions of the virtual atoms only. The procedure was recycled until convergence.

At the end of the refinement of the virtual-atom model against the theoretical data, the $R(F)$ factor was 0.58 and $0.45 \%$ for the refinements without and with $\kappa$ core correction.

3.3.3. Virtual atoms: experimental refinement. The initial model was from the experimental multipolar refinement, to which the virtual atoms were added. The atoms were set as monopolar and the initial charge density set to the IAM model. The values of the $U^{i j}$ parameters for $\mathrm{H}$ atoms were fixed as taken from the $S H A D E$ server (Madsen, 2006). The anisotropic $U^{i j}$ values of the bond virtual atoms were not refined, but constrained to take the average $U^{i j}$ values of the two bonding atoms. The $U^{i j}$ values of the lone pairs were constrained to ride on the $U^{i j}$ values of the carrier atom.

The following strategy was used for the charge-density refinement using the virtual atoms model against the experimental data:

(a) Initially the scale factor was refined, followed by the refinement of positions of all atoms including the hydrogen and the virtual atoms. Then $U^{i j}$ displacement parameters were refined for all atoms except for the hydrogen and the virtual atoms.

(b) In order to properly deconvolute the thermal motion and deformation of the electron density, the position and the $U^{i j}$ parameters of the real non- $\mathrm{H}$ atoms were refined at high order using reflections with $\sin \theta / \lambda$ between 0.7 and $1.03 \AA^{-1}$.

(c) In the last stage, the valence populations and the $\kappa$ parameters were refined successively using all data until convergence. The optimal values of the sigmas (0.02) obtained from the $R_{\text {free }}$ refinements were used for the chemical equivalence restraints applying to kappas and the valence populations. 
Table 2

Statistics on the Fourier residual maps after the refinements using the different models.

The reciprocal resolution used is $s<1.25 \AA^{-1}$ for theory and $s<1.03$ for the experiment. MUL $\_\kappa_{\text {core }}$ and VIR_ $\kappa_{\text {core }}$ refer to the kappa core refinement.

\begin{tabular}{llllll}
\hline Data refinement & $\Delta \rho_{\min }$ & $\Delta \rho_{\max }$ & r.m.s $(\Delta \rho)$ & $\begin{array}{l}w R_{2}(F) \\
(\%)\end{array}$ & $\begin{array}{l}R(F) \\
(\%)\end{array}$ \\
\hline EXP_IAM & -0.75 & 0.75 & 0.099 & 5.62 & 5.25 \\
EXP_MUL & -0.64 & 0.66 & 0.081 & 3.21 & 4.23 \\
EXP_VIR & -0.68 & 0.50 & 0.083 & 4.43 & 4.37 \\
THEO_IAM & -0.67 & 1.02 & 0.085 & 2.77 & 1.61 \\
THEO_MUL & -0.75 & 0.17 & 0.024 & 0.77 & 0.74 \\
THEO_VIR & -0.48 & 0.34 & 0.020 & 0.66 & 0.58 \\
THEO_MUL_ $\kappa_{\text {core }}$ & -0.32 & 0.21 & 0.013 & 0.45 & 0.33 \\
THEO_VIR_ $\kappa_{\text {core }}$ & -0.31 & 0.32 & 0.018 & 0.57 & 0.45 \\
\hline
\end{tabular}

(d) The $\mathrm{Lp}-\mathrm{O} 1-\mathrm{Lp}$ angle subtended at the $\mathrm{O}$ atom was restrained to $140^{\circ}$ on the basis of the values obtained from the refinement of the same model using the theoretical structure factors as the unrestrained refinement left a peak at the position of the lone pairs.

At the end of the refinement of the virtual-atom model against the experimental data, the $R(F)$ value was $4.4 \%$.

\section{Results and discussion}

\subsection{Residual Fourier density and refinement statistics}

A comparison of the crystallographic statistics is given in Table 2 and residual Fourier electron densities of different refinements are shown in Figs. 3, 4 and 5. As expected, the values show that the spherical atom model refinement has the highest $R$ factor and r.m.s. residual density, whereas the multipolar refinement shows the best statistics.

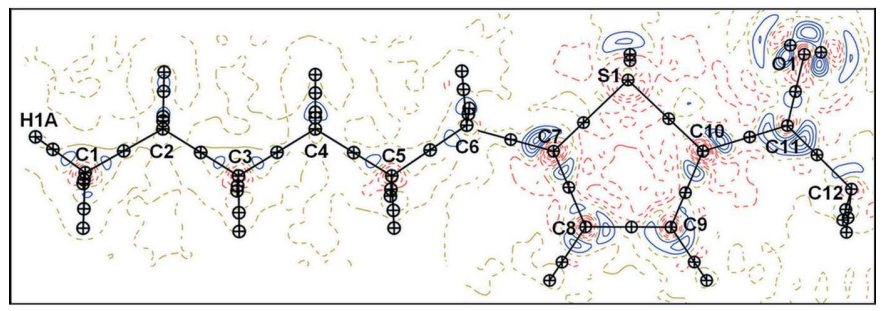

(a)

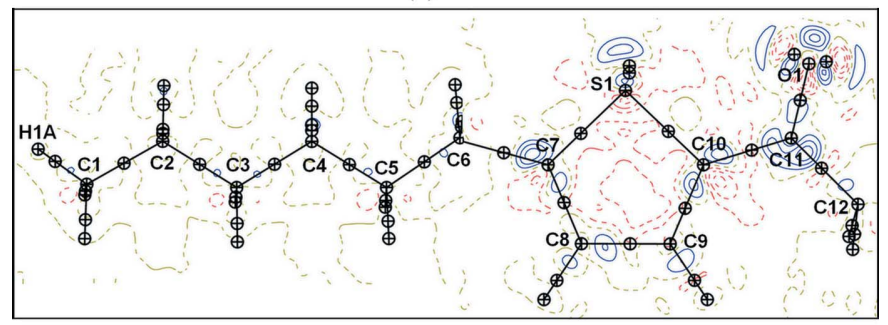

(b)

Figure 5

Fourier residual map for the THEO_VIR refinements: $(a)$ without and (b) with kappa core correction. Resolution used: $s<1.2 \AA^{-1}$. Contours as in Fig. 3.
The experimental residual densities for the multipolar (MUL) and virtual (VIR) atom models are shown in Figs. 3(a) and $3(b)$, respectively. The two maps are very similar and show no large traces of remaining electron density, except around the $\mathrm{S}$ atom.

Fig. 4 shows, for the theoretical data, the residual electron densities when using the multipolar atom models without (Fig. 4a), and with (Fig. 4b) correction of the kappa core parameter. In order to highlight the need for the correction of kappa core, a higher resolution range up to $s<1.2 \AA^{-1}$ is used. It can be noticed that when the correction for the kappa core is not made, more electron density is left around the nuclei, which has disappeared after the correction is applied as already discussed (Pillet et al., 2001). Compared with the experimental data, there are no strong peaks of residual density close to the sulfur atom. However, more residual density is observed around the atom nuclei and on the covalent bonds when no kappa core parameter is refined. This certainly highlights the need for an improvement in the radial functions used for the refinement versus theoretical $F_{h k l}$.

A similar pattern is noticed for the case of the virtual-atom modelling refined against the theoretical data. A correction for the kappa core also shows a significant improvement both in $R$ factors (Table 2) and in the residual electron density around the nuclei (Figs. $5 a$ and $b$ ).

The refinement statistics (Table 2) show that when no kappa core correction is applied, the virtual-atom model THEO_VIR yields better $\Delta \rho_{\min }$ and r.m.s. $(\Delta \rho)$ values than the multipolar atom model THEO_MUL. However, the value of $\Delta \rho_{\max }$ is higher than for the multipolar model, indicating that some positive electron density is left un-modelled.

For the theoretically generated structure factors, the multipolar model also leads to the best refinement. The statistics are significantly improved by the refinement of a kappa parameter for the core electrons. The virtual-atom model shows improved refinement statistics compared with the IAM, but the multipolar model performs slightly better.

\subsection{Crystal structure and packing}

The molecule is centrosymmetric with an inversion centre lying at the midpoint of the $\mathrm{C} 12-\mathrm{C} 12 \mathrm{~A}$ bond. The carbothienyl portion of the molecule is planar whereas the hexyl chain portion is slightly twisted and lies out of the plane. The torsion angle between the thienyl ring and the terminal

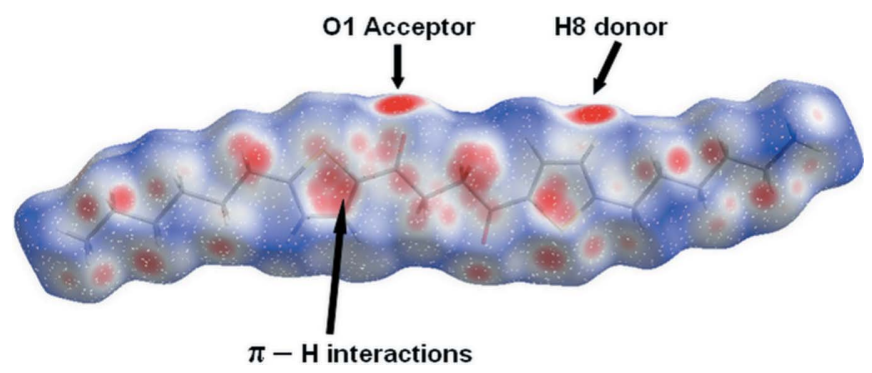

Figure 6

Hirshfeld surface mapped with $d_{\text {norm }}$. 
Table 3

Nature of contacts at the Hirshfeld surface and enrichment ratios.

The enrichment numbers given in italic characters are not meaningful as they are ratios of small surfaces.

\begin{tabular}{lllllllllll}
\hline Interaction & $\mathrm{CC}$ & $\mathrm{CH}$ & $\mathrm{CO}$ & $\mathrm{CS}$ & $\mathrm{HH}$ & $\mathrm{HO}$ & $\mathrm{HS}$ & $\mathrm{OO}$ & $S$ & $\mathrm{OS}$ \\
\hline \% contacts & 0.3 & 14.2 & 0.2 & 0.8 & 60.0 & 12.3 & 11.9 & 0 & 0 & 0.3 \\
\% surface & 7.9 & & & & 79.2 & & & 6.4 & 6.5 & \\
Enrichment & 0.48 & 1.13 & 0.20 & 0.78 & 0.96 & 1.21 & 1.16 & 0.00 & 0.00 & 0.36
\end{tabular}

portion of the hexyl chain is $17.58(4)^{\circ}$. The molecules are stacked over each other in the form of sheets which run in parallel to each other in three dimensions. The interplanar distance between two successive layers of the molecules is $3.55 \AA$ (plane calculated using the thienyl ring of the molecule). The molecular packing is supported by a large number of short interactions and weak hydrogen bonds. There are $\mathrm{H} \cdots \mathrm{H}, \mathrm{H} \cdots \mathrm{S}$ and $\mathrm{C}-\mathrm{H} \cdots \pi$ contacts between the molecules.

Hirshfeld surface analysis is a convenient way to study the intermolecular interactions (Spackman \& Jayatilaka, 2009). The quantity $d_{\text {norm }}$ is computed at a surface point using the distances to the nearest interior $\left(d_{\mathrm{i}}\right)$ and exterior $\left(d_{\mathrm{e}}\right)$ atoms and the van der Waals radii of the atoms (McKinnon et al., 2007)

$$
d_{\mathrm{norm}}=\frac{d_{\mathrm{i}}-r_{\mathrm{i}}^{\mathrm{vdW}}}{r_{\mathrm{i}}^{\mathrm{vdW}}}+\frac{d_{\mathrm{e}}-r_{\mathrm{e}}^{\mathrm{vdW}}}{r_{\mathrm{e}}^{\mathrm{vdW}}}
$$

If $d_{\text {norm }}$ is negative, the sum $d_{\mathrm{i}}+d_{\mathrm{e}}$, i.e. the contact distance, is shorter than the sum of the van der Waals radii of the atoms. Fig. 6 shows the surface regions where the acceptors and donors for the hydrogen bonds are located. The red colour shows the region where the intermolecular distance between two atoms is shorter than the sum of their van der Waals radii. It is apparent there are large numbers of interactions with the neighbouring molecules.

According to the fingerprint plot (Fig. S3), the majority of the interactions are of the $\mathrm{H} \cdots \mathrm{H}$ type, followed by $\mathrm{C} \cdots \mathrm{H}$, $\mathrm{O} \cdots \mathrm{H}$ and $\mathrm{S} \cdots \mathrm{H}$ types (Table 3 ). The enrichment ratios (Jelsch et al., 2014) of atomic contacts in the crystal packing have been computed. The enrichment for a given pair of chemical species $X \cdots Y$ is the ration between the actual amount of contact surface and that of equiprobable contacts computed from the chemical composition on the Hirshfeld surface. The ratios are larger than unity for the $\mathrm{O} \cdots \mathrm{H}, \mathrm{S} \cdots \mathrm{H}$ and $\mathrm{C} \cdots \mathrm{H}$ contacts indicating that these interactions are slightly overrepresented. These are favourable electrostatic hydrogen bonds and $\pi \cdots H$ interactions. In contrast, $\mathrm{H} \cdots \mathrm{H}$ which represents $60 \%$ of the contact surface appears slightly disfavoured in this crystal packing, owing to competition with the $\mathrm{C}-\mathrm{H} \cdots \mathrm{O}$ and $\mathrm{C}-\mathrm{H} \cdots \mathrm{S}$ weak hydrogen bonds which are more polar and are presumably the driving force in the crystal packing formation.

The $\mathrm{H} 2 A$ atom makes a short contact with the $\mathrm{H} 2 A$ atom of a neighbouring molecule at a distance of $2.320 \AA$ (Table 4). The $\mathrm{H} 2 B$ atom on the other hand makes a bifurcated interaction with the $\mathrm{H} 3 A$ and $\mathrm{H} 5 A$ atoms of an adjacent molecule
Table 4

List of hydrogen bonds and shortest contacts in the crystal packing.

Distances $(\AA)$ and angles $\left({ }^{\circ}\right)$ are given for the EXP_MUL model. The symmetry code applies to the acceptor atom.

\begin{tabular}{lllll}
\hline$D-\mathrm{H} \cdots A$ & $\begin{array}{l}\mathrm{H} \cdots A \\
(\AA)\end{array}$ & $\begin{array}{l}D \cdots A \\
(\AA)\end{array}$ & $\begin{array}{l}D-\mathrm{H} \cdots A \\
\left({ }^{\circ}\right)\end{array}$ & Symmetry code \\
\hline $\mathrm{C} 8-\mathrm{H} 8 \cdots \mathrm{O} 1$ & 2.301 & $3.095(4)$ & 128.6 & $x, y+1, z$ \\
$\mathrm{C} 12-\mathrm{H} 12 A \cdots \mathrm{S} 1$ & 2.970 & $3.586(4)$ & 116.0 & $x+1, y, z$ \\
$\mathrm{C} 12-\mathrm{H} 12 A \cdots \mathrm{C} 10$ & 2.863 & $3.646(5)$ & 128.7 & $x+1, y, z$ \\
$\mathrm{C} 3-\mathrm{H} 3 B \cdots \mathrm{S} 1$ & 2.937 & $3.924(4)$ & 150.5 & $x-1, y+1, z$ \\
$\mathrm{C} 2-\mathrm{H} 2 A \cdots \mathrm{H} 2 A$ & 2.320 & 3.106 & 123.3 & $-x-2,-y+2,-z+1$ \\
$\mathrm{C} 6-\mathrm{H} 6 B \cdots \mathrm{C} 10$ & 2.806 & 3.695 & 138.5 & $x-1, y, z$ \\
\hline
\end{tabular}

at a distance of 2.352 and $2.356 \AA$, respectively, and the $\mathrm{H} 3 A-$ $\mathrm{H} 2 B-\mathrm{H} 5 A$ angle is $65.63^{\circ}$.

The $\mathrm{H} 5 B$ atom makes an intermolecular $\mathrm{C}-\mathrm{H}$. . O-type hydrogen bond with the $\mathrm{O} 1$ atom at a $d_{\mathrm{HO}}$ distance of $2.689 \AA$ and the $\mathrm{C} 5-\mathrm{H} 5 B \cdots \mathrm{O} 1$ angle of $159.04^{\circ}$ is nearly linear. The $d_{\mathrm{HO}}$ distance lies at the margin between a weak hydrogen bond and a van der Waals interaction according to the criteria laid down by Desiraju \& Steiner (1999).

The $\mathrm{O} 1$ atom also makes a stronger intermolecular $\mathrm{C}-$ $\mathrm{H} \cdots \mathrm{O}$ hydrogen bond with $\mathrm{H} 8$ atom at a distance $d_{\mathrm{HO}}=$ $2.301 \AA$ (Fig. 7), which is quite a lot shorter than the sum of the van der Waals radii $(2.6 \AA)$. The C8...O 1 distance, which is 3.095 (5) $\AA$ in this interaction, is also significantly short. The $\mathrm{C} 8-\mathrm{H} 8 \cdots \mathrm{O} 1$ angle is $128.6^{\circ}$; this is common in such types of interaction where the angle is far from linearity owing to the weak nature of the interaction (Desiraju \& Steiner, 1999). However, the geometry of this $\mathrm{C} 8-\mathrm{H} 8$. . O 1 hydrogen bond is quite consistent with the conclusion drawn by Bernstein et al. (1974) that $\mathrm{C}-\mathrm{H} \cdots \mathrm{O}$ interactions are 'lateral' in crystal structures of planar molecules. The $\mathrm{C} 8-\mathrm{H} 8 \cdots \mathrm{O} 1$ interaction

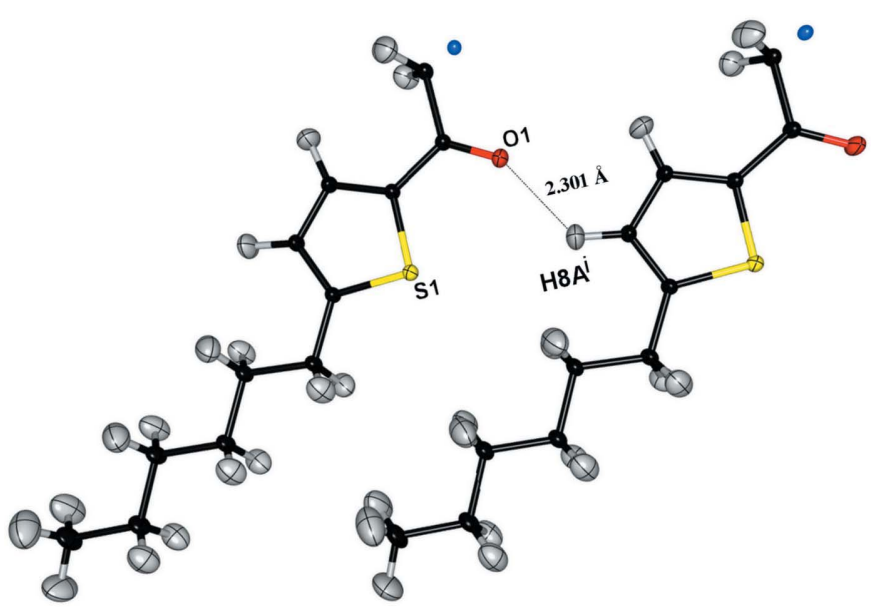

Figure 7

Auto-stereogram view (Katrusiak, 2001) of the displacement ellipsoids of the asymmetric unit of the title compound at a 50\% probability level. The $b$ axis is horizontal towards the left. The two molecules are related by $b$ axis translation and the $\mathrm{C} 8-\mathrm{H} 8 \cdots \mathrm{O} 1$ hydrogen bond is shown. The view is generated with the program MoProViewer (Guillot, 2011). The blue sphere denotes the inversion centre of the molecule, where a symmetric atom $\mathrm{C} 12 \mathrm{~A}$ forms a covalent bond with $\mathrm{C} 12$. 


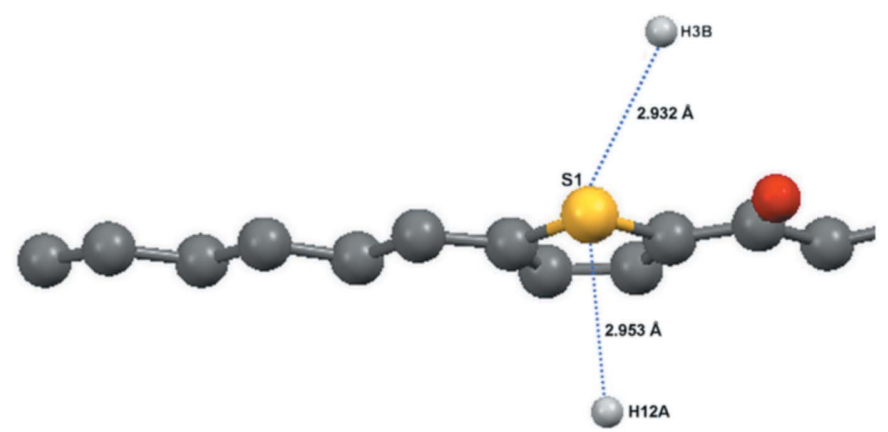

Figure 8

Hydrogen bonding towards lone pairs of the thiophene $\mathrm{S}$ atom. Only the donor $\mathrm{H}$ atoms are shown for clarity. Symmetry operations: H12A, $x-1$, $y, z ; \mathrm{H} 3 B: x+1, y-1, z$.

is the strongest polar interaction in the crystal packing and should play a crucial role in the close packing of this molecule.

The thienyl ring is acting as a strong $\pi$ acceptor and forms intermolecular $\mathrm{C}-\mathrm{H} \cdots \pi$ interactions with its neighbouring molecules. On one side of the reference molecule, $\mathrm{H} 12$ forms a $\mathrm{C}-\mathrm{H} \cdots \pi$ interaction with $\mathrm{C} 9$ and $\mathrm{C} 10$ atoms of the aromatic ring at distances of 2.889 and $2.863 \AA$, respectively. Similarly on the other side, the $\mathrm{H} 6 B$ atom interacts with the $\mathrm{C} 10$ atom at a distance of $2.806 \AA$. As in an aromatic ring, all the atoms of the thienyl moiety can act as $\pi$ acceptors (Desiraju \& Steiner, 1999).

The shape and orientation of the lone pairs have consequences for the hydrogen-bonding propensity and molecular interactions with the $\mathrm{S}$ atoms. The hydrogen bonds show generally a preference to orient themselves in the direction of the lone pairs. According to the orientation of the $\mathrm{H} 3 B \cdots \mathrm{S} 1$ interaction, the hydrogen bonding with the $\mathrm{S}$ atom for this thiophene compound follows the general tendency of directionality towards the electron lone pairs (Fig. 8).

The S1 atom forms a weak hydrogen bond with an $\mathrm{H} 3 B$ atom at a distance of $2.937 \AA$, the $\mathrm{S} 1 \cdots \mathrm{H} 3 B$ interaction is this time well aligned to the direction of the $\mathrm{S}$ lone pair (Fig. 8). This is a typical example of the directionality of the hydrogen bonding to the lone pairs of $\mathrm{S}$ atoms.

On the opposite side, the H12A atom interacts with the S1 atom in a direction nearly perpendicular to the thienyl plane. The $\mathrm{H} 12 A \cdots \mathrm{S} 1$ interaction could be both of $\mathrm{C}-\mathrm{H} \cdots \pi$ and hydrogen-bonding types, as the thienyl $\mathrm{S}$ atom has lone pairs which are oriented nearly perpendicularly to the plane of the aromatic ring. This crystal structure shows that the thienyl ring is a potential $\pi$ acceptor. A survey of the CCDC supports these observations. There are only three entries in the CCDC with a similar motif (EGOJEP, RUHZOJ, XIPZIF).

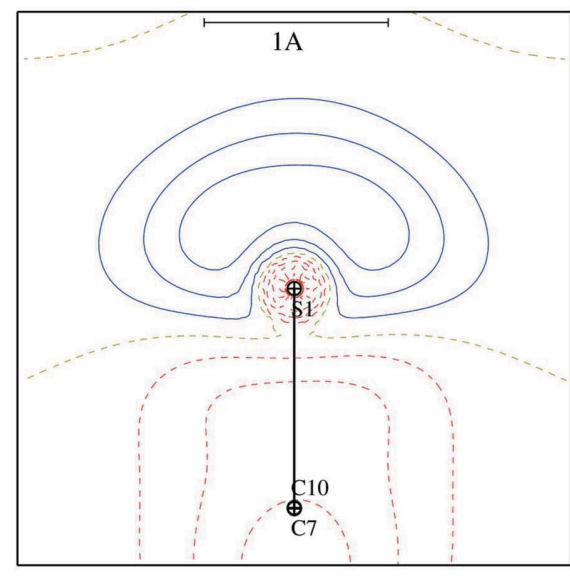

(a)

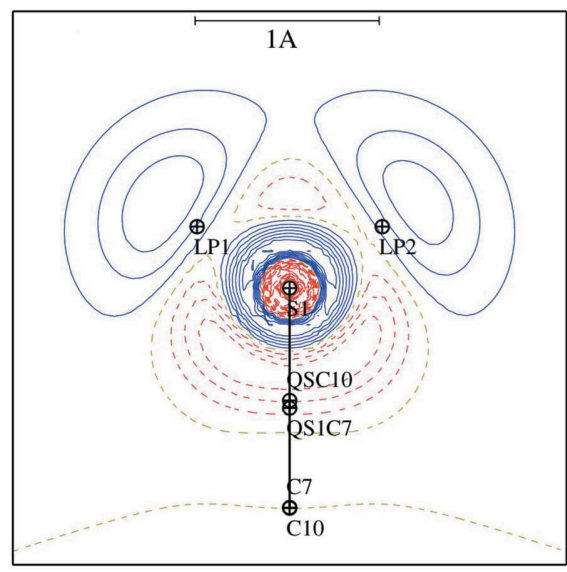

$(d)$

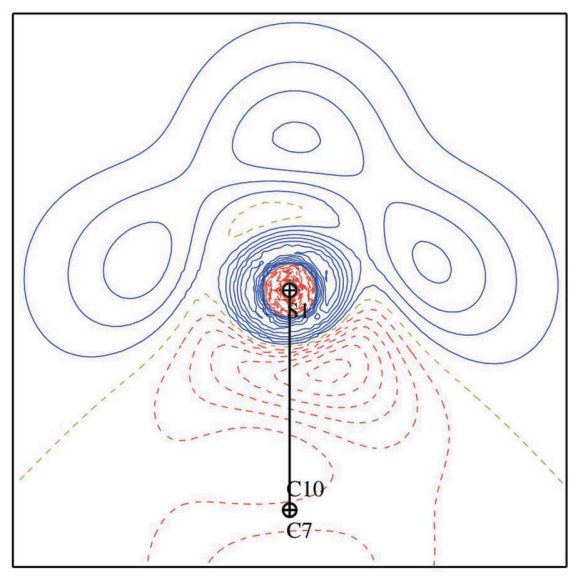

(b)

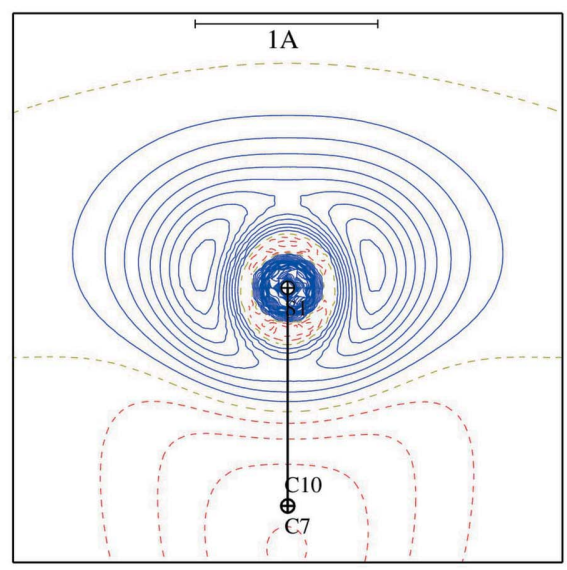

(e)

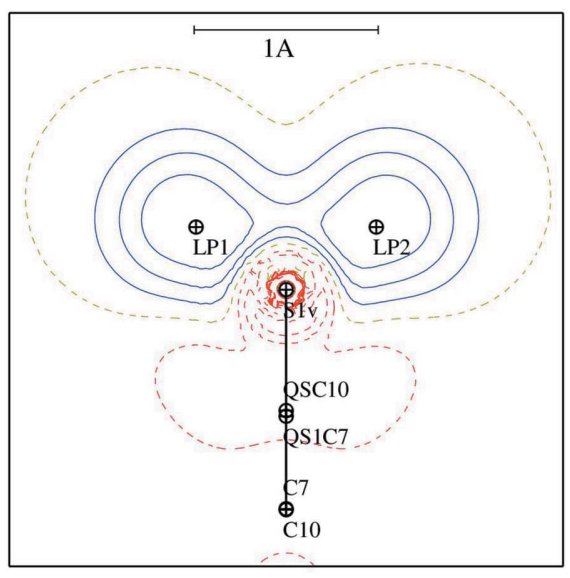

(c)

Figure 9

Electron density in the lone pairs plane of the $\mathrm{S}$ atom with different models. Contours $\left( \pm 0.05\right.$ e $\left.\AA^{-3}\right)$ : (a) THEO_MUL_ $\kappa_{\text {core }},(b)$ EXP_MUL, (c) THEO_VIR_ $\kappa_{\text {core }}, \quad(d)$ EXP_VIR and $(e)$ experimental in the $\mathrm{Cs} p^{3}-\mathrm{Csp}^{3}$ environment of methionine (Guillot et al., 2001). 


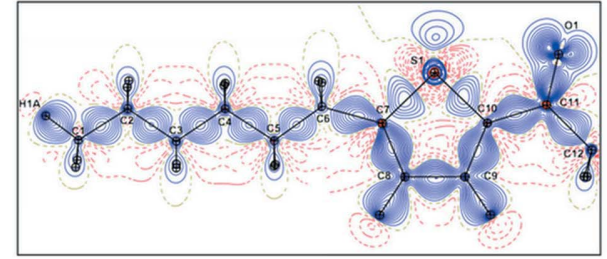

(a)

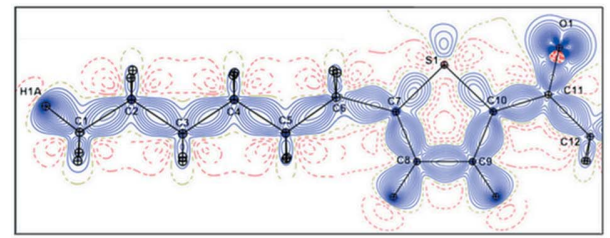

(c)

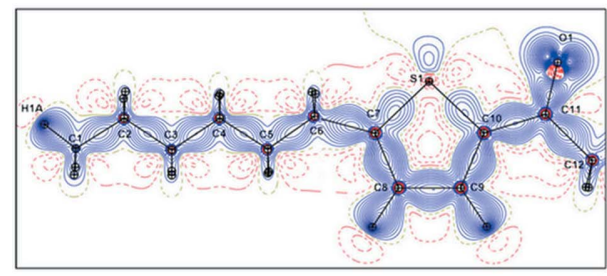

(e)

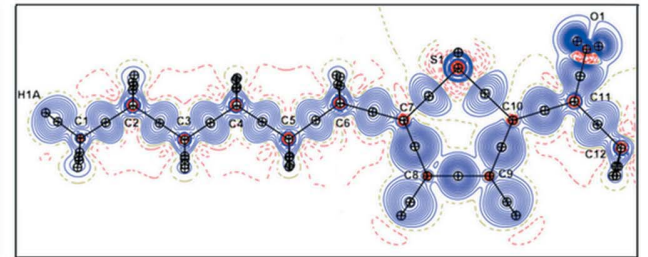

(b)

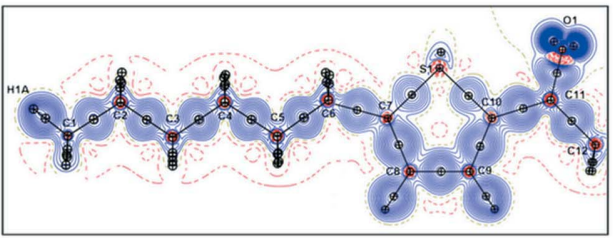

(d)

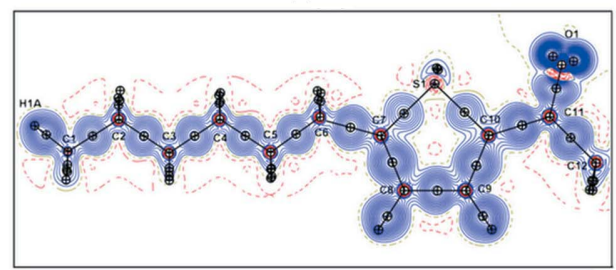

$(f)$

Figure 10

Static deformation electron density maps. Multipolar atom model: (a) EXP_MUL, (c) THEO_MUL and $(e)$ THEO_MUL_ $\kappa_{\text {core }}$.Virtual-atom model: $(b)$ EXP_VIR, $(d)$ THEO_VIR and $(f)$ THEO_VIR_ $\kappa_{\text {core. }}$ Contour level is at \pm 0.05 e $\AA^{-3}$.

\subsection{Charge density}

The electron density maps from experiment and theory are in good agreement. In the experimental deformation density maps, the electron lone pairs on the sulfur atom in the thienyl moiety are oriented, as expected, in the plane bisecting the $\mathrm{C}-\mathrm{S}-\mathrm{C}$ bonds, perpendicular to the aromatic ring (Fig. 9). As compared with the model obtained after refinement against theoretical data, the lone pairs in the experimental map are more diffused away from the nucleus and bent laterally outwards. The sulfur lone pairs in thiophene are in a $s p^{2}$ environment, whereas in methionine (Guillot et al., 2001) they are in an $s p^{3}$ environment. As a consequence of the aromatic environment, the sulfur lone pairs can be expected to be closer to each other compared with those in methionine (Ahmed, Jelsch et al., 2013).

Fig. 10 shows a comparative representation of the static deformation electron densities of various models. The maps, in general, are in good agreement with each other. The multipolar theoretical models show deformation density which is more elongated along the covalent bonds compared with the multipolar experimental model. The values of the total density and Laplacian on the bond critical points are however comparable (see Figs. S3, S4 and S5; supporting information). Globally, the r.m.s. value of the deformation electron density on the molecule is $37 \%$ higher with THEO_MUL_ $\kappa_{\text {core }}$ model compared with EXP_MUL, due to the elongated bonding density in the former model.
A residual electron density peak is observed in the thiophene ring near the S1 atom for the experimental data (MUL and VIR refinement, Fig. 3) but is not present in the theoretical maps (Figs. 4 and 5).

The Lp1-S-Lp2 angle was restrained to $109.5(5)^{\circ}$ to obtain meaningful density of the sulfur lone pairs in the EXP_VIR refinement. The lone pairs on the S1 atom in the VIR model are then similar in experiment and theory; however, it has to be recalled that the results are dependent on what is modelled initially. The multipolar atom model is much more flexible to model extended densities as observed in the EXP_MUL and EXP_THEO refinements (Fig. 10).

The density on the electron lone pairs of the carbonyl oxygen is found to be greater for the VIR model compared with the MUL model in the different refinements in Fig. 10.

4.3.1. Intermolecular interactions. A quantitative analysis of the intermolecular interactions was performed in terms of topology of the electron density (Bader, 1990; Bader et al., 1987). The interactions are listed in Table S1 (supporting information). The Hirshfeld surface analysis shows that there are four types of interactions: $\mathrm{CH} \cdots \mathrm{HC}, \mathrm{CH}$ $\cdots \mathrm{S}, \mathrm{CH} \cdots \mathrm{O}$ and $\mathrm{CH} \cdots \pi$.

The asymmetric unit comprising half a molecule is in direct contact with 13 neighbouring entities. There are 27 unique intermolecular critical points (CPs) found for these four types of interactions within an interatomic distance of $4.0 \AA$.

The same intermolecular CPs were generally found for the three models (Fig. 11 and Table S1 in the supporting information), except for two $\mathrm{H} \cdots \mathrm{C}$ interaction CPs. A good correlation is found for the electron density $\rho\left(\mathbf{r}_{\mathrm{CP}}\right)$ and its Laplacian $\nabla^{2} \rho\left(\mathbf{r}_{\mathrm{CP}}\right)$ between the different models. The correlation coefficients between the theoretical and the experimental multipolar atom models for $\rho\left(\mathbf{r}_{\mathrm{CP}}\right)$ and for its Laplacian $\nabla^{2} \rho\left(\mathbf{r}_{\mathrm{CP}}\right)$ are 0.980 and 0.992 , respectively. Similarly, the correlation coefficients between the theoretical and the experimental virtual-atom models for $\rho\left(\mathbf{r}_{\mathrm{CP}}\right)$ and its Laplacian $\nabla^{2} \rho\left(\mathbf{r}_{\mathrm{CP}}\right)$ are 0.971 and 0.995 , respectively. If the experimental multipolar and experimental virtual-atom models are compared, the correlation coefficients for the electron density and its Laplacian are found to be 0.958 and 0.995 , respectively. The values from the topological analysis show, in general, good agreement with each other for the three models, but some systematic differences appear. The average electron density at the CPs is significantly higher for the EXP_MUL 


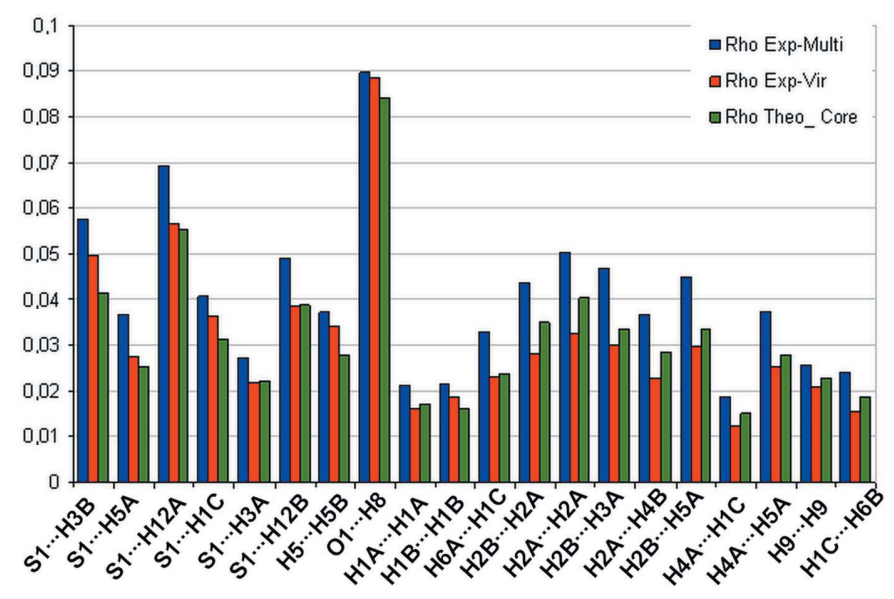

Figure 11

Electron densities at the intermolecular critical points of three models: EXP_MUL, EXP_VIR and THEO_MUL_ $\kappa_{\text {core }}$.

model $\left\langle\rho\left(\mathbf{r}_{\mathrm{CP}}\right)\right\rangle=0.040$ e $\AA^{-3}$ compared with the EXP_VIR

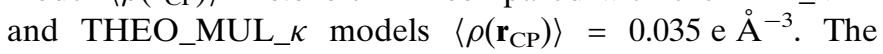
electron density $\rho\left(\mathbf{r}_{\mathrm{CP}}\right)$ on $\mathrm{H} \cdots \mathrm{H}$ interactions is almost systematically lower for the EXP_VIR model than for THEO_MUL_ $\kappa$, which is itself lower than EXP_MUL.

Therefore, as recently discussed (Lecomte et al., 2015), charge-density modelling of intermolecular interactions is an accurate tool for quantifying the intermolecular interactions by going a step further than only comparing the distances of the intermolecular interactions.

4.3.2. Electrostatic potential. The electrostatic properties around the molecule can be qualitatively described by colouring the molecular surface according to the potential value. The electron-withdrawing effect of the carbonyl group causes the drifting of electron density towards the centre of the molecule. Whereas the electron-donating effect of the alkyls makes the hexyl chain electrostatically positive [Figs. 12(a)-(c)]. There is a distinct negative electrostatic area on S1 and O1 which corresponds very well with the electro-

(a) THEO_MUL

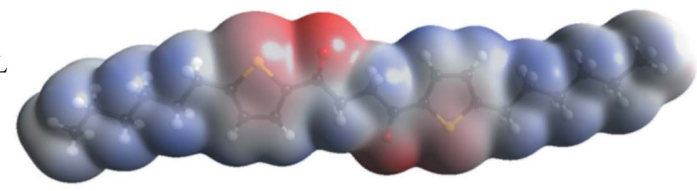

(b) EXP_MUL

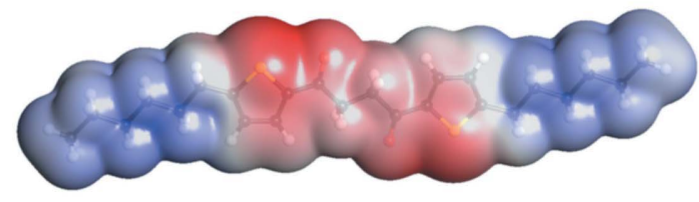

(c) EXP_VIR

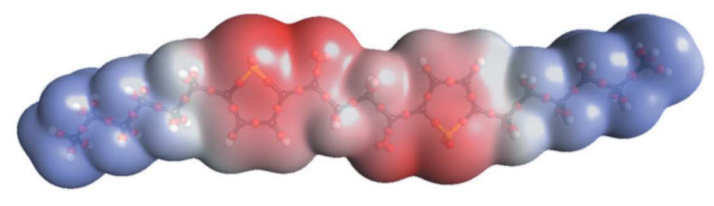

Figure 12

Electrostatic potential on the molecular surface fixed at an electron density value of $0.005 \mathrm{e}^{-3}$ : (a) THEO_MUL_ $\kappa_{\text {core }}$, (b) EXP_MUL and (c) EXP_VIR. negativity of $\mathrm{O}$ and $\mathrm{S}$ atoms and the presence of lone pairs of electrons on these two atoms.

The electrostatic potential mapped on the isosurface of electron density value 0.005 e $\AA^{-3}$ is shown in Figs. 12(a)-(c). The virtual-atom model is also used to calculate the electrostatic potential which is compared with the multipolar atom model. Although there are small quantitative differences between the different models, they are qualitatively in good agreement with each other. For the calculation of the electrostatic potential, the virtual-atom model is found to behave in a similar way to the multipolar atom model and, therefore, could be easily applied to high-resolution protein diffraction data.

\section{Conclusion}

The experimental electron density analysis of the title compound was performed using subatomic resolution X-ray diffraction data. The experimental results were also compared with the charge density refined against theoretically generated structure factors. The charge density derived from the experimental data is found to be in good agreement with the theoretical results.

In the case of theoretical structure factors, it was found advantageous to refine a supplementary parameter, the expansion/contraction of the core electron shell to compensate for different functions used to describe the electron density in the quantum calculations and in the crystallographic refinement. The refinement of a $\kappa$-core parameter significantly improves the quality of the modelling in terms of refinement statistics and Fourier residual electron density near the nuclei.

A dummy bond charge model, based on the simplification of the multipolar atom model, is also used for the refinement. This model can be used as an alternative to the multipolar one and it reduces the number of refined parameters. The refinement $R$-factor statistics and the Fourier residual electron density statistics show that the dummy bond charge model is a considerably better modelling than the spherical atom model (IAM), but the multipolar atom model yields the best results.

However, the VIR model sometimes needs careful refinement strategies for the electron lone pairs. Also, as expected, it is not well suited to the topological analysis of the covalent bonds (Nassour et al., 2014). As it was among the first trials of this model, some shortcomings are noticed, but for instance an elliptical modelling of virtual atoms would be a possible improvement which would involve three more parameters to refine per virtual atom.

The DBC significantly reduces the number of refined parameters compared with the more classical MUL/multipolar model and might be used to refine the charge density for compounds with diffraction data measured at lower resolution.

A database to model the electron density in proteins and common chemical groups is under construction. This VIR database uses charge densities of organic compounds in the crystalline phase refined versus theoretical $F_{h k l}$ values such as in the current study. A database transfer then allows us to 
calculate the electrostatic properties, for example, in case of protein structures.

The electrostatic potential calculated for the title compound shows that qualitatively the virtual-atom model is in very good agreement with the multipolar model. It is assumed, on the basis of this study, that the virtual-atom model will be helpful in calculating the electrostatic properties of proteins in a more rapid manner than with the MUL model.

A VIR database is also easier to connect with the concept of atomic point charges widely used in molecular mechanics software than a multipolar atoms database. The inclusion of additional zero-mass point charges around electronegative atoms, such as oxygen, in locations of the chemically intuitive electron lone pair have been proposed in molecular mechanics calculations. The increase in the number of charge sites results in an overall improvement in the energy associated with the angular dependence of hydrogen bonds (Dixon \& Kollman, 1997). For instance, the inclusion of lone pair charges in the TIP5P water model increases its ability to reproduce both gasphase and condensed-phase properties over its non-Lp predecessor, TIP3P (Tschampel et al., 2007).

\section{Acknowledgements}

MA thanks the Higher Education Commission of Pakistan for PhD funding.

\section{References}

Afonine, P. V., Grosse-Kunstleve, R. W., Adams, P. D., Lunin, V. Y. \& Urzhumtsev, A. (2007). Acta Cryst. D63, 1194-1197.

Afonine, P. V., Lunin, V. Y., Muzet, N. \& Urzhumtsev, A. (2004). Acta Cryst. D60, 260-274.

Agilent (2010). CrysAlisPro. Agilent Technologies Ltd, Yarnton, England.

Ahmed, M., Jelsch, C., Guillot, B., Lecomte, C. \& Domagała, S. (2013). Cryst. Growth Des. 13, 315-325.

Ahmed, M., Yar, M., Nassour, A., Guillot, B., Lecomte, C. \& Jelsch, C. (2013). J. Phys. Chem. A, 117, 14267-14275.

Allen, F. H. (1986). Acta Cryst. B42, 515-522.

Altomare, A., Cascarano, G., Giacovazzo, C. \& Guagliardi, A. (1993). J. Appl. Cryst. 26, 343-350.

Bader, R. F. W. (1990). Atoms in Molecules: A Quantum Theory. Oxford: Clarendon Press.

Bader, R. F. W., Carroll, M. T., Cheeseman, J. R. \& Chang, C. (1987). J. Am. Chem. Soc. 109, 7968-7979.

Barbarella, G., Melucci, M. \& Sotgiu, G. (2005). Adv. Mater. 17, 15811593.

Batke, K. \& Eickerling, G. (2013). J. Phys. Chem. A, 117, 1156611579.

Becke, A. D. (1993). J. Chem. Phys. 98, 5648-5652.

Bentley, J. \& Stewart, R. F. (1974). Acta Cryst. A30, 60-67.

Bernstein, J., Cohen, M. D. \& Leiserowitz, L. (1974). The Chemistry of the Quinonoid Compounds, Part 1, edited by S. Patai, pp. 37-110. New York: Interscience.

Bindzus, N., Straas $\varnothing$, T., Wahlberg, N., Becker, J., Bjerg, L., Lock, N., Dippel, A.-C. \& Iversen, B. B. (2014). Acta Cryst. A70, 39-48.

Blessing, R. H. (1997). J. Appl. Cryst. 30, 421-426.

Brünger, A. T. (1992). Nature, 355, 472-475.

Brünger, A. T. (1997). Methods Enzymol. 277, 366-396.

Clark, R. C. \& Reid, J. S. (1995). Acta Cryst. A51, 887-897.

Clementi, E. \& Roetti, C. (1974). At. Data Nucl. Data Tables, 14, 177478.
Dadda, N., Nassour, A., Guillot, B., Benali-Cherif, N. \& Jelsch, C. (2012). Acta Cryst. A68, 452-463.

Desiraju, R. \& Steiner, T. (1999). Structural Chemistry and Biology. Oxford University Press.

Dixon, R. W. \& Kollman, P. A. (1997). J. Comput. Chem. 18, 1632 1646.

Domagała, S. \& Jelsch, C. (2008). J. Appl. Cryst. 41, 1140-1149.

Dovesi, R., Saunders, V. R., Roetti, C., Orlandol, R., Zicovich-Wilson, C. M., Pascale, F., Civalleri, B., Doll, K., Harrison, N. M., Bush, I. J., D'Arco, Ph. \& Llunell, M. (2008). CRYSTAL06 1.0, Version 1_0_2. University of Turin, Italy.

Ellinger, S., Ziener, U., Thewalt, U., Landfester, K. \& Möller, M. (2007). Chem. Mater. 19, 1070-1075.

Farrugia, L. J. (1997). J. Appl. Cryst. 30, 565.

Farrugia, L. J. \& Senn, H. M. (2012). J. Phys. Chem. A, 116, 738746.

Fischer, A., Tiana, D., Scherer, W., Batke, K., Eickerling, G., Svendsen, H., Bindzus, N. \& Iversen, B. B. (2011). J. Phys. Chem. A, 115, 13061-13071.

Fritz, S. E., Mohapatra, S., Holmes, B. T., Anderson, A. M., Prendergast, C. F., Frisbie, C. D., Ward, M. D. \& Toney, M. F. (2007). Chem. Mater. 19, 1355-1361.

Gál, Z., White, F., Griffin, A., Presly, O., Thompson, A. \& Frampton, C. (2011). Acta Cryst. A67, C754.

González, S. R., Casado, J., Navarrete, J. T. L., Blanco, R. \& Segura, J. L. (2008). J. Phys. Chem. A, 112, 6732-6740.

Guillot, B. (2011). Acta Cryst. A67, C511-C512.

Guillot, B., Viry, L., Guillot, R., Lecomte, C. \& Jelsch, C. (2001). J. Appl. Cryst. 34, 214-223.

Hansen, N. K. \& Coppens, P. (1978). Acta Cryst. A34, 909-921.

Hariharan, P. C. \& Pople, J. A. (1973). Theor. Chim. Acta, 28, 213 222.

Hirshfeld, F. L. (1976). Acta Cryst. A32, 239-244.

Hohenberg, P. \& Kohn, W. (1964). Phys. Rev. B, 136, 864-871.

Ie, Y., Han, A., Otsubo, T. \& Aso, Y. (2009). Chem. Commun. pp. 3020-3022.

Izawa, T., Miyazaki, E. \& Takimiya, K. (2009). Chem. Mater. 21, $903-$ 912.

Izumi, T., Kobashi, S., Takimiya, K., Aso, Y. \& Otsubo, T. (2003). J. Am. Chem. Soc. 125, 5286-5287.

Jelsch, C., Guillot, B., Lagoutte, A. \& Lecomte, C. (2005). J. Appl. Cryst. 38, 38-54.

Johnson, C. K. \& Burnett, M. N. (1996). ORTEPIII. Report ORNL6895. Oak Ridge National Laboratory, Tennessee, USA.

Katrusiak, A. (2001). J. Mol. Graph. Model. 19, 363-367.

Lecomte, C., Espinosa, E. \& Matta, C. F. (2015). IUCrJ, 2, 161-163.

Lee, C., Yang, W. \& Parr, R. G. (1988). Phys. Rev. B, 37, 785-789.

Le Page, Y. \& Gabe, E. J. (1979). J. Appl. Cryst. 12, 464-466.

Madsen, A. Ø. (2006). J. Appl. Cryst. 39, 757-758.

Madsen, A. Ø., Sørensen, H. O., Flensburg, C., Stewart, R. F. \& Larsen, S. (2004). Acta Cryst. A60, 550-561.

McKinnon, J. J., Jayatilaka, D. \& Spackman, M. A. (2007). Chem. Commun. p. 3814.

Nassour, A., Kubicki, M., Wright, J., Borowiak, T., Dutkiewicz, G., Lecomte, C. \& Jelsch, C. (2014). Acta Cryst. B70, 197-211.

Nicolas, Y., Blanchard, P., Roncali, J., Allain, M., Mercier, N., Deman, A. L. \& Tardy, J. (2005). Org. Lett. 7, 3513-3516.

Oliva, M. M., Pappenfus, T. M., Melby, J. H., Schwaderer, K. M., Johnson, J. C., McGee, K. A., da Silva Filho, D. A., Bredas, J.-L., Casado, J. \& López Navarrete, J. T. (2010). Chem. Eur. J. 16, 68666876.

Overgaard, J., Jones, C., Dange, D. \& Platts, J. A. (2011). Inorg. Chem. 50, 8418-8426.

Paul, A., Kubicki, M., Jelsch, C., Durand, P. \& Lecomte, C. (2011). Acta Cryst. B67, 365-378.

Perepichka, I. F. \& Perepichka, D. F. (2009). Editors. Handbook of Thiophene-Based Materials: Applications in Organic Electronics and Photonics, Vol. 1-2. New York: John Wiley \& Son. 
Pillet, S., Souhassou, M., Lecomte, C., Schwarz, K., Blaha, P., Rérat, M., Lichanot, A. \& Roversi, P. (2001). Acta Cryst. A57, 290303.

Ponomarenko, S. \& Kirchmeyer, S. (2003). J. Mater. Chem. 13, $197-$ 202.

Scheringer, C. (1980). Acta Cryst. A36, 205-210.

Scheringer, C., Kutoglu, A., Mullen, D. \& Hellner, E. (1978). Acta Cryst. A34, 475-476.

Sheldrick, G. M. (2008). Acta Cryst. A64, 112-122.

Spackman, M. A. \& Jayatilaka, D. (2009). CrystEngComm, 11, 1932.
Stewart, R. F. (1976). Acta Cryst. A32, 565-574.

Tschampel, S. M., Kennerty, M. R. \& Woods, R. J. (2007). J. Chem. Theory Comput. 3, 1721-1733.

Yamamoto, T. \& Takimiya, K. (2007). J. Am. Chem. Soc. 129, 2224 2225.

Zarychta, B., Zaleski, J., Kyzioł, J., Daszkiewicz, Z. \& Jelsch, C. (2011). Acta Cryst. B67, 250-262.

Zhang, X., Côté, A. P. \& Matzger, A. J. (2005). J. Am. Chem. Soc. 127, 10502-10503.

Zhurov, V. V., Zhurova, E. A. \& Pinkerton, A. A. (2008). J. Appl. Cryst. 41, 340-349. 